\title{
LA SÁTIRA QUEVEDESCA CONTRA LUIS PACHECO DE NARVÁEZ
}

\author{
Aurelio Valladares Reguero \\ UNED. Centro Asociado de Úbeda (Jaén)
}

\section{RESUMEN}

El objetivo del presente trabajo es la presentación y comentario de media docena de textos de Quevedo escritos contra el célebre maestro de esgrima Luis $\mathrm{Pa}$ checo de Narváez, con quien mantuvo de por vida un virulento enfrentamiento. Tras algunas consideraciones sobre dicho personaje y las obras con que éste, a su vez, contraatacó a su rival, el estudio se centra en los referidos textos del autor madrileño, que constituyen, por su variedad y tratamiento, un ejemplo ilustrativo de la técnica quevedesca en el manejo de la sátira, género en el que supo emplear todo tipo de recursos lingüísticos; en claro contraste con las armas dialécticas utilizadas, en esta ocasión, por su adversario.

\section{INTRODUCCIÓN}

El enfrentamiento entre Quevedo y el maestro de esgrima Luis Pacheco de Narváez constituye uno de los ejemplos más representativos de las rivalidades existentes en el ambiente cultural de la Villa y Corte de Madrid durante el primer tercio del siglo XVII, justo cuando allí convivía - aunque no siempre en buena armonía - la flor y nata del Parnaso español. Y supone, por otra parte, 
una vía de acercamiento a la obra satírica del genial autor madrileño, parcela capital, aunque no exclusiva — por supuesto-, de su producción.

No se trata de un simple incidente, sino de una enemistad nunca disimulada por ambas partes, ya que fue plasmada en diversos escritos, perdurando durante más de tres décadas, y a la que sólo pudo poner fin la muerte de $\mathrm{Pa}$ checo de Narváez en 1640, cuando Quevedo afrontaba el duro trance de su reclusión en San Marcos de León, ya en la recta final de su vida.

Algunos estudiosos del célebre autor madrileño-manchego, en especial A. Fernández Guerra, han cargado las tintas negativas, en modo tan excesivo como injusto -creo-, sobre la personalidad del citado maestro de armas; como si la fama del autor del Buscón precisara rebajar en todo lo posible la de su rival, extremo que parece a todas luces innecesario. Más ponderada me parece la opinión de Pablo Jauralde Pou en su reciente biografía quevedesca, al apuntar que Pacheco de Narváez era un hombre respetado en los ambientes literarios de la época, lo cual se ajusta mucho más a la realidad.

El objeto del presente trabajo es el conjunto de escritos satíricos de Quevedo contra el referido maestro de esgrima. Ahora bien, parece procedente ver primero quién era este personaje, lo que sin duda nos ayudará a comprender mejor los textos quevedescos que analizaremos a continuación; deteniéndonos, como es lógico, en aquellos aspectos que puedan servirnos para el propósito indicado'.

\section{Síntesis bio-bibliográfica de Luis Pacheco de Narváez}

Debo comenzar precisando que no estamos ante una primera figura de las letras españolas del Siglo de Oro. Sus incursiones en el terreno estrictamente literario fueron sólo una pequeña parte de su producción, que estuvo dedicada, casi por entero, a los tratados sobre la destreza de las armas. Ahora bien, sí hay que afirmar que en esta materia (muy en boga entonces) fue durante mucho tiempo referente inexcusable, incluso fuera de España, extremo que avalan las sucesivas ediciones de sus obras. Por otra parte -y este detalle me parece especialmente relevante-, conviene tener presente que goz6 de la amistad de los literatos más renombrados del momento, si bien esta situación ha quedado bas-

1 Sobre este particular puede verse mi trabajo (1999) «Luis Pacheco de Narváez: Apuntes bio-bibliográficos», Boletín del Instituto de Estudios Giennenses, n. ${ }^{\circ} 173$, pp. 509-577. Aprovecho la ocasión para advertir el excesivo número de erratas que se deslizaron, muchas de ellas inexplicables para mi, fruto de las prisas que motivaron la salida a la luz de la publicación, sin las oportunas pruebas de corrección, al menos en mi caso. 
tante ensombrecida por la virulenta relación que mantuvo con uno de ellos, Francisco de Quevedo, hasta el punto de que, en ocasiones, ha podido parecer que es ésta la única faceta reseñable de su biografía. En consecuencia, un análisis detenido, a la vez que desapasionado, del problema resulta la forma más adecuada para comprenderlo en su justa medida. Se trata, en definitiva, de poner a cada uno en el lugar que le corresponde. Y bajo esta perspectiva voy a intentar orientar la presente exposición.

No ofrece la menor duda que Luis Pacheco de Narváez nació en la ciudad de Baeza (Jaén), según consta en varios documentos y en la portada de su primera obra publicada. Esto debió de ocurrir hacia 1570, si tenemos en cuenta el dato de los «treinta años» que Pacheco confiesa haber servido al Rey cuando en 1624 solicita el título de Maestro mayor de las armas, suponiendo que hubiera entrado en la milicia con unos 16 años.

A finales de siglo se encontraba destinado como «sargento mayor» en las Islas Canarias, servicio del que siempre se sintió orgulloso, por lo que no dudo en argumentarlo al cursar la solicitud a la que acabo de hacer referencia.

Durante la estancia en el archipiélago canario redactó su Libro de las grandezas de la espada, con cuyo original se trasladó a Madrid en 1599, abrigando sin duda la esperanza de que la publicación de esta obra lo consagrara en los ambientes culturales de la Corte como teorizador de la materia y le abriera nuevas perspectivas profesionales. Tras asumir no pocos riesgos económicos (se conservan varios documentos al respecto), la obra salió a la luz en 1600 con un buen número de poemas laudatorios, varios de los cuales corresponden a personajes naturales o residentes en Canarias, lo que revela la buena fama que allí dejaba.

A partir de esta fecha, la vida del escritor quedará ligada a la capital madrileña, donde desarrollará una intensa actividad literaria, que no cesará hasta el momento de su muerte. En efecto, a la obra mencionada siguieron otras más, algunas con varias ediciones: Las cien conclusiones o formas de saber de la verdadera destreza (Madrid, Luis Sánchez, 1608); Compendio de la filosofía y destreza de las armas, de Gerónimo de Carranza (Madrid, Luis Sánchez, 1612); Modo fácil y nuevo para examinarse los maestros en la destreza de las armas (Madrid, Luis Sánchez, 1625); Engaño y desengaño de los errores que se han querido introducir en la destreza de las armas (Madrid, Imprenta del Reino, 1635); la novela costumbrista Historia ejemplar de las dos constantes mujeres españolas (Madrid, Imprenta del Reino, 1635); Advertencias para la enseñanza de la filosofía y destreza de las armas (Madrid, Pedro Tazo, 1639), y Nueva ciencia y filosofía de la destreza de las armas, su teórica y práctica (Madrid, Melchor Sánchez, 1672). A esta relación deben unirse varios textos más, tanto manuscritos como impresos, obras perdidas de las que existen va- 
gas referencias y algún poema suelto; sin olvidar los escritos directamente dirigidos contra Quevedo, de los que hablaré más adelante.

Cada nueva publicación en materia de esgrima era ocasión para reafirmar teorías anteriores suyas y criticar las opiniones contrarias, manteniendo viva una polémica que no parecía cesar. Precisamente, la aparición de su segunda obra, Las cien conclusiones (1608), motivó el famoso incidente entre Pacheco y Quevedo, relatado por el biógrafo de éste, Pablo Antonio de Tarsia, en los siguientes términos:

Hallòse Don Francisco en vn concurso de los mayores Señores de la Corte en casa del Presidente de Castilla, donde se arguyd sobre las cien conclusiones de la destreza de las armas, que sacò Don Luis Pacheco de Naruaez, Maestro, que fue del Rey nuestro Señor en esta profession, y mayor en los Reynos de España; y despues de auer discurrido algunos, e impugnado las conclusiones, salio Don Francisco contradiziendo la que en vn genero de acometimiento dezia no auer reparo, ni defensa; y para la prueba, combidò al Maestro, à que tomasse con el la espada; el qual, aunque lo reusaua, alegando, que la Academia se auia juntado para pelear con la razon, y no con la espada, obligaronle sin embargo los Señores à salir con ella, y al primer encuentro le dio Don Francisco en la cabeça, derribandole el sombrero. Retiròse el Naruaez algo enojado del sucesso; y Don Fra[n]cisco, para saçonar la fiesta, dixo: Probò muy bien el señor D. Luis Pacheco la verdad de su conclusion, que à auer reparo en este acometimiento no le pegàra yo.

(Vida de don Francisco de Quevedo y Villegas, Madrid, Pablo de Val, 1663, pp. 59-60).

Generalmente suele apuntarse este hecho como el inicio del odio, público y manifiesto, que mantuvieron de por vida los dos escritores. No obstante, es presumible que la enemistad viniera de antes, si tenemos en cuenta (lo veremos en su momento) la posible alusión satírica al baezano en $E l$ sueño del juicio final de Quevedo, redactado antes del mencionado incidente.

A pesar de todo, la fama de Pacheco crecía y esto le llevó a solicitar y conseguir el título de Maestro mayor de las armas, concedido por el Rey en 1624. Como ya se ha indicado, el baezano argumentó (y se le reconoció) los treinta años de servicio a Su Majestad, así como el haber reducido a ciencia la destreza de las armas y que fuystes el primero que me [el Rey] pusistes la espada en la mano siendo mi maestro (Archivo Histórico Nacional, Decretos del Consejo de la Cámara, $1624, n .^{\circ} 53$ ). Lograba así una preciada plaza, que conllevaba el derecho de examinar a todos los maestros de armas. 
Este título, que Pacheco mostraba con orgullo, haciéndolo constar en la portada de las obras que publicaba, motivó de inmediato la inquina de los maestros de armas de la Corte y del Reino, que no dudaron en entablar un pleito contra él. De todo lo relativo a este asunto dio cumplida referencia Cristóbal Pérez Pastor, por lo que no voy a entrar en más detalles.

Singular importancia reviste, para el caso que ahora nos ocupa, la noticia de un hecho que podría corresponder a la etapa final de la vida de Luis Pacheco de Narváez. Se trata de un escrito anónimo publicado por Antonio Rodríguez Villa (1886) ${ }^{2}$, en el que, relatando lo ocurrido en Madrid entre los días 18 y 25 de octubre de 1636, se dice que D. Luis de Narváez está preso por haber compuesto y dado a la estampa una comedia en prosa, que constituye una crítica feroz contra Quevedo. Por esta razón se sospecha que fuera el propio Quevedo el causante del apresamiento, lo que éste niega, si bien agrega que, cuando don Luis salga de la cárcel, está dispuesto a desafiarlo y darle muerte, «por muy gran maestro de esgrimir que sea don Luis».

La opinión de los críticos sobre este particular no es coincidente. Rodríguez Villa, en una nota insertada en su edición, opina que el tal Luis de Narváez era un poeta cortesano del que se conocen algunas composiciones. Otros estudiosos, por el contrario, no dudan en afirmar que el baezano fue el protagonista del referido hecho, ya que encaja perfectamente en el contexto de enemistad que había entre ambos. Por mi parte, mantengo serias dudas de que se trate de nuestro personaje, porque si bien es cierto que algunos detalles parecen indicarlo, nada se sabe hasta la fecha de esa supuesta «comedia» en prosa contra Quevedo a la que se alude; aparte de lo apuntado por Rodríguez Villa. Es más, pienso que las características de dicho texto -se desconoce su paternidad- suscitan sospechas sobre la autenticidad de lo que en él se afirma.

De la muerte de Pacheco de Narváez nos da noticia el cronista ( $y$ amigo suyo) José Pellicer y Tobar:

El día de antes [miércoles, 5 de diciembre de 1640] había muerto el famoso Don Luis Pacheco de Narváez, Maestro mayor de España y del Rey nuestro Señor, que mandó al Señor Patriarca le hiciese decir 500 Misas.

(Avisos históricos, que comprehenden las noticias y sucesos más particulares, ocurridos en nuestra Monarquía desde el año de 1639,

2 La Corte y la Monarquía en los años de 1636 y 37..., Madrid, Luis Navarro Editor, pp. 5758. El texto ha sido reproducido y comentado por varios estudiosos de Quevedo. Felicidad Buendía recoge un fragmento en su edición de las Obras completas. Verso de F. DE QUEVEDo (p. 950). 
publicados por Antonio Valladares de Sotomayor en el Semanario erudito, Madrid, Antonio Espinosa, 1790, p. 252).

$\mathrm{Al}$ igual que otros insignes escritores (algunos de ellos amigos suyos, como Lope de Vega, Ruiz de Alarcón o Vélez de Guevara), fue enterrado en la parroquia madrileña de San Sebastián, muy cercana a su domicilio de la calle de las Huertas, que tenía en alquiler desde marzo de 1635. El acta de defunción reza así:

D. Luis Pacheco de Narbaez viudo, calle de las Huertas en las casas de Sanchez murio en seis de diciembre de 1640 años. Recibió los Santos Sacramentos y testó ante Fran[cis]co de Talabera en dos deste mes. Missas a boluntad de Ju[an] Andrea Calbo en dicha casa pago de fabrica en el Colegio diez y seis reales. [En el margen:] missas a boluntad. (Libro de Difuntos, Tomo 9, fol. 38v).

Aunque aquí se dice que murió el día 6, parece claro que debe tomarse como fecha del entierro, ya que según Pellicer había fallecido el día anterior.

Asimismo, son muy importantes otros detalles reflejados en dicha acta, en especial lo relativo al testamento. Lógicamente, he intentado por todos los medios su localización, pero sin resultado positivo. En el Archivo Histórico de Protocolos de Madrid no se encuentra ningún legajo de la escribanía del mencionado Francisco de Talavera. También he recurrido, dada la relación de Pacheco con los reyes Austrias, al Archivo General de Simancas e, incluso, al del Palacio Real de Madrid, pero con idéntica suerte. Hubiera sido de enorme interés contar con este documento, ya que habría proporcionado muchos datos sobre su vida, que, además, podrían haber servido para iniciar otras vías de investigación.

Por otra parte, en el acta de defunción consta que era viudo, pero nada he podido llegar a conocer sobre su situación familiar: nombre de la esposa, fecha de su fallecimiento, posibles hijos, etc. El hecho de que los gastos del sepelio fueran efectuados por Juan Andrea Calvo lleva a deducir que, al menos en el momento de la muerte, no tenía herederos directos. Mantengo la esperanza de que algún día se pueda hallar este testamento, que seguramente nos aclarará estos y otros muchos pormenores.

La vida de Pacheco de Narváez fue una continua lucha en defensa de sus teorías sobre la destreza de las armas. Contó con el éxito de sus libros, algunos de los cuales consiguieron varias ediciones, incluso después de su muerte, lo que demuestra la popularidad de que gozaron. Hizo, asimismo, incursiones meritorias en otros terrenos más específicamente literarios, como es el caso de la novela Historia ejemplar o el de la obra dialogística Peregrinos discursos. Se vio gratificado con el reconocimiento de los más afamados autores del momento (Lope 
de Vega, Vélez de Guevara, Ruiz de Alarcón, Pérez de Montalbán, Valdivielso, Suárez de Figueroa, Calderón de la Barca, López de Zárate, Herrera Maldonado, Polo de Medina, Ovando y Santarén, Juan Bautista Diamante, José Pellicer y un largo etcétera), amén de notables tratadistas de esgrima que siguieron inequívocamente su estela. Este dato contrasta de forma meridiana con el de los autores que lo criticaron, nómina en la que sólo podemos apuntar a Bartolomé Leonardo de Argensola (con un soneto cuyo contenido matizó de inmediato), dos tratadistas de esgrima y Quevedo. Incluso cabe apuntar la circunstancia de su inclusión en la relación de «autoridades» del primer Diccionario de la Academia Española, que más tarde refrendaría en el Catálogo de Autoridades publicado por la docta institución en 1874. Traigo a colación estos datos, muchas veces pasados por alto, para resaltar que el rival al que se enfrent 6 el célebre autor madrileño, si bien está muy por debajo de la categoría literaria de éste, no era - ni mucho menosun «enemigo pequeño», como en ocasiones se ha querido hacer ver.

De todas formas, la fina pluma de Quevedo se bastaba por sí sola para no arredrarse ante nada y ante nadie. Y esto fue lo que ocurrió con el maestro de armas baezano, que tuvo que sufrir sus hirientes puyazos. Por otra parte, su hoja de servicios lo había acreditado para que el rey le concediera el prestigioso título de Maestro mayor de las armas, pero, igualmente, tuvo que soportar la envidia y el recelo de quienes no estaban dispuestos a reconocer las atribuciones que este cargo llevaba consigo. Y, para que nada le faltara, las dificultades económicas fueron asiduas compañeras de viaje hasta el mismo lecho de la muerte.

Como remate de este esbozo biográfico, creo conveniente reproducir un fragmento de las Advertencias para la enseñanza de la filosofía y destreza de las armas (1639), su última obra publicada en vida, donde puede verse una confesión que, en buena medida, resume estos avatares:

El hombre que se entrega a los estudios no cura de su hacienda, pues he gastado la mía (que era más que mediana) sirviendo a $S$. $M$. en esta corte y fuera de ella, hasta conducirme a tan suma pobreza, que carezco (afírmolo con verdad) aun de lo que al más miserable mendigo le sobra, por no haber conseguido no sólo el premio de mi servir, pero ni aun el más limitado socorro para poderme alimentar un día. (Edic. de 1898, p. 136).

\section{Obras de Pacheco contra Quevedo}

Son tres las obras escritas por el baezano contra Quevedo, aunque alguna presenta problemas sobre su autoría real o total. Además, conviene resaltar que 
se trata de escritos bastante tardíos; es decir, cuando entra en liza Pacheco, Quevedo - como luego se comprobará - ya había arremetido contra él en varias ocasiones.

1. Memorial de... denunciando al Tribunal de la Inquisición ciertas obras políticas y satírico-morales de don Francisco de Quevedo. Manuscrito original y autógrafo, escrito hacia 1630. Fue adquirido en 1859 por Aureliano Fernández-Guerra, por cuya gentileza lo publicó Menéndez Pelayo y más tarde Luis Astrana Marín.

En él se hace una denuncia del contenido de cuatro libros de Quevedo: Política de Dios (Zaragoza, 1626), Historia de la vida del Buscón (Barcelona, 1626), Sueños y discursos de verdades (Zaragoza, 1627) [concretamente, el Sueño del juicio final y El alguacil endemoniado] y Discurso de todos los diablos o infierno enmendado (Gerona, 1628).

Aunque la mayoría de los críticos no han dudado de la paternidad de este escrito, Fermín Vegara Peñas (1929) ${ }^{3}$ sostiene que los verdaderos autores fueron otros dos enemigos declarados de Quevedo, Fr. Diego Niseno y Juan Pérez de Montalbán, y que el baezano se limitó a poner su nombre. Por mi parte, considero que el hecho de que la Política de Dios fuera unos años después el objetivo central de la crítica de Pacheco en sus Peregrinos discursos viene a corroborar que el Memorial salio de la pluma de nuestro autor, con independencia de que pudiera haber contado con alguna otra colaboración.

A. Fernández-Guerra, siempre muy severo en sus juicios sobre Pacheco, afirma, en tono no exento de acritud, que este escrito no tuvo ninguna repercusión en el tribunal de la Inquisición. Sin embargo, F. Vegara considera que, una vez entregado el Memorial, en 1631, la Inquisición prohibió todas las obras de Quevedo impresas hasta ese año, en tanto el autor no las reformase. La duda está en saber si esta actuación se debió exclusivamente al escrito del baezano, ya que otras personas también habían intervenido para que el Santo Oficio vetara las obras del célebre autor madrileño.

2." Arnaldo Franco-Furt: El Tribvnal de la ivsta vengança, erigido contra los Escritos de D. Francisco de Queuedo, Maestro de Errores, Doctor en Desverguenças, Licenciado en Bufonerías, Bachiller en Suciedades, Cathedratico de Vizios, y Proto-Diablo entre los Hombres (Valencia, Herederos de Felipe Mey, 1635).

3 «Don Luis Pacheco de Narváez (Notas para su biografía)», Don Lope de Sosa, n. 197, pp. 141-142. 
Es una crítica feroz, como ya revela el propio título, desarrollada bajo la siguiente ficción literaria: llega a Sevilla un correo anunciando la Perinola de Quevedo. Un cuadernillo manuscrito cae en manos de «seis varones doctos», que determinan constituir un tribunal que se llamará de la justa venganza. Quevedo, al encontrarse ausente, estará representado por un abogado. Se celebran seis audiencias, a través de las cuales van apareciendo los distintos cargos que se le imputan. Los ataques se dirigen fundamentalmente contra varias de las obras del madrileño: Buscón, Sueños, Discursos de todos los diablos y Juguetes de la niñez y travesuras del ingenio. También se mencionan El mundo por dentro, Visita de los chistes, Cartas del caballero de la tenaza y Cuento de los cuentos. Al final se hace constar que queda erigido el tribunal por si el encausado reincide en sus delitos, para proceder contra él en primera instancia, al tiempo que se ordena que de lo aquí advertido se dé cuenta al Tribunal de la Santa Inquisición y al Supremo Consejo de Justicia.

Aunque no hay coincidencia entre los estudiosos, son varios (particularmente, especialistas en Quevedo) los que creen que, bajo el seudónimo de Arnaldo Franco-Furt, se esconden Fr. Diego Niseno, Juan Pérez de Montalbán y Luis Pacheco de Narváez, sin olvidar a otros enemigos del célebre autor madrileño residentes en Sevilla. Fermín Vegara (art. cit., pp. 168-171) hace un detenido análisis de esta cuestión.

Es evidente que el baezano se encontraba entre los más acérrimos enemigos de Quevedo, quien no había desperdiciado ocasión para burlarse de él. Entra, pues, dentro de lo posible que nuestro autor tomara parte, de una u otra forma, en la publicación. No obstante, las críticas de esta obra contra el escritor madrileño rezuman una acritud que difiere bastante de la ponderación que se observa en la refutación que hace Pacheco en sus Peregrinos discursos de otro libro de Quevedo, lo que me hace dudar de que fuera también el artífice directo de la obra ahora reseñada, si bien esto no excluye algún otro tipo de implicación. En cualquier caso, se aprecian algunas relaciones entre esta obra y otras del baezano. Por ejemplo, en El tribunal son criticados varios escritos quevedianos que Pacheco había denunciado previamente en el Memorial y en los Peregrinos discursos podemos encontrar algunas citas utilizadas en El tribunal.

Hay, incluso, investigadores (es el caso, por ejemplo, de P. Jauralde Pou) que piensan que esta obra es la «comedia en prosa» a la que se alude en el escrito anónimo publicado por Rodríguez Villa.

3." Peregrinos discursos y tardes bien empleadas. Por Don... Maestro del Rey Nuestro Señor en la Philosophia y Destreza de las Armas (1640). Manus- 
crito. Cuenta con algunas aprobaciones para su publicación, que, sin embargo, no se llevó a cabo, muy posiblemente porque la muerte del autor a finales de dicho año lo impidió.

La obra está redactada en forma de diálogo, que mantienen unos peregrinos que regresan desde Santiago de Compostela hacia la Corte, y en ella trata de refutar los fundamentos teóricos de la Política de Dios, que ya con anterioridad había incluido Pacheco, junto a otras obras quevedescas, en el Memorial ya citado.

Participan en el debate, durante cinco jornadas, cinco peregrinos procedentes de distintos lugares de España (un sacerdote andaluz, un jurista de Castilla la Vieja, un humanista de Castilla la Nueva, un soldado extremeño y un cortesano), a los que se unirán en las tres jornadas últimas dos ermitaños andaluces expertos en Derecho Civil y Canónico, respectivamente. De los siete contertulios sólo el cortesano, que se confiesa amigo del autor de la Política de Dios, defiende este libro, en tanto que los restantes van rebatiendo los puntos fundamentales de la referida obra, cada uno desde el campo de su especialidad, hasta que al final terminan sacando al cortesano de su error. La argumentación se hace con gran aparato crítico, fundamentado en todo tipo de fuentes: Sagrada Escritura, Santos Padres, autores clásicos, reconocidos teólogos y juristas... Aparte de esto, se ve una clara intención por parte del autor de indisponer a su rival con el rey Felipe IV y el Conde Duque de Olivares. Es de resaltar que en ningún momento de la obra aparece el nombre de Quevedo. Simplemente se habla del «autor» de la Política de Dios.

A esta obra, totalmente desconocida hasta hace bien poco, he dedicado recientemente dos artículos, que se complementan con una edición crítica (Pamplona, EUNSA, 1999).

\section{II. Textos de Quevedo contra Pacheco de Narváez}

Llegamos, por fin, al tema central del presente trabajo. Pido disculpas por haberme extendido un poco más de lo normal, pero, como ya advertía al principio, me ha parecido de obligada referencia.

Aparte del incidente entre ambos personajes ocurrido en 1608 y el de 1636 -éste más dudoso-, ya comentados, ninguno de los dos escritores perdió ocasión de afrentar a su rival en el campo literario. Al Memorial y los Peregrinos discursos de Pacheco de Narváez (sin olvidar su posible implicación en El tribunal de la justa venganza), se contraponen, por parte de Quevedo, las obras que se detallan a continuación. 


\section{$1 .{ }^{a}$ El sueño del juicio final}

En el desfile de personajes que salen de la tumba para comparecer en el juicio final encontramos a un maestro de esgrima en el que tradicionalmente se ha visto retratado a Pacheco de Narváez, si bien no todos comparten esta opinión.

Llegó en esto un hombre desaforado y con ceño, y alargando la mano dijo:

- Esta es la carta de examen.

Admiráronse todos y dijeron los porteros que quién era; y él en altas voces respondi6:

- Maestro de esgrima, examinado y de los más diestros del mundo, y sacando otros papeles de un lado dijo que aquellos eran los testimonios de sus hazañas; cayéronsele en el suelo por descuido los testimonios y fueron a un tiempo a levantarlos dos diablos y un alguacil, y él los levantó primero que los diablos. Llegó un ángel y alargó el brazo para asirle y meterle dentro, y él retirándose alargó el suyo y dando un salto dijo:

- Esta de puño es irreparable, y si me queréis probar yo daré buena cuenta.

Riéronse todos y un oficial algo moreno le preguntó qué nuevas tenía de su alma; pidiéronle no sé qué cosas y respondió que no sabía tretas contra los enemigos de ella. Mandáronle que se fuese por línea recta al infierno, a lo cual replicó diciendo que debían de tenerlo por diestro del libro matemático, que él no sabía qué era línea recta; hiciéronselo aprender y diciendo: - Entre otro- se arrojó.

(Sueños y discursos, edic. de Felipe C. R. Maldonado, Madrid, Castalia, 1972, pp. 77-78).

Como apunta Maldonado en una nota de su edición, este texto, escrito antes de 1608 (fecha del famoso incidente entre ambos), muestra que la animadversión de Quevedo hacia el baezano era más antigua; suponiendo - como hace el mencionado crítico- que sea Pacheco el maestro de esgrima que aparece aquí.

En contra de esta opinión, aceptada por varios editores de la obra quevediana, se ha pronunciado más recientemente Ignacio Arellano, quien afirma que el maestro de esgrima al que se refiere Quevedo no responde a ningún personaje histórico concreto y que «no es ni puede identificarse con don Luis Pacheco de Narváez, ya que pertenece a la otra vertiente caricaturesca que articula en Quevedo la sátira del maestro de los espadachines» ${ }^{4}$.

4 Cfr. «El diestro del Juicio final, de QUEVEDo, y su identidad», en Busquemos otros montes y otros ríos. Estudios de literatura española del Siglo de Oro dedicados a Elías L. Rivers, Madrid, Castalia, 1992, pp. 11-17 (la cita corresponde a la p. 17). 
Debo indicar que me parecen muy oportunas las observaciones de Arellano, ya que, en efecto, dicho maestro de esgrima replica en una de sus intervenciones que lo habían confundido con un «diestro del libro matemático» y «que él no sabía qué era línea recta». Es decir, estaríamos ante un representante de la destreza «primitiva» o «vulgar», en oposición a los partidarios de la destreza "verdadera», con apoyatura teórica en términos matemáticos, corriente a la que sí pertenecía el maestro baezano.

No obstante, pienso que este pasaje nos proporciona algunos detalles muy reveladores que me hacen intuir que Quevedo sí pudo redactarlo pensando en Pacheco de Narváez; sobre todo si lo relacionamos con el texto del Buscón que vamos a ver a continuación, donde no existe ninguna duda sobre la alusión al baezano. Son varias las coincidencias entre ambos pasajes: el maestro se enorgullece de su condición, en tanto que los demás se ríen de él; se le caen los papeles que lo acreditan como tal (en el Buscón es él el que se cae); aparece en ambos la expresión «línea recta»; da saltos cuando se ejercita en tales teorías; será un «oficial algo moreno» (en el Buscón se habla de un «mulatazo») quien se enfrente a él... Téngase en cuenta, además, que esta obra de Quevedo sería después una de las denunciadas en el Memorial de Pacheco.

Por todo ello entiendo que, si bien resulta evidente que a quien pone en ridículo Quevedo es a un representante de la destreza vulgar, de paso, lanza también sus ataques contra los partidarios de la «destreza verdadera», cuyo máximo representante era el baezano, que ya había publicado en $1600 \mathrm{su}$ monumental Libro de las grandezas de la espada. Es bien significativo que el maestro de este pasaje, cuando le hablan de «línea recta», indique que lo han debido de confundir con un «diestro del libro matemático», es decir, el de Pacheco. Se ve claramente, pues, cómo Quevedo tampoco aceptaba esta otra vertiente, por lo que nos encontraríamos ante un anticipo del incidente entre ambos en casa del Presidente de Castilla.

\section{2.' El Buscón}

En el capítulo I del libro II se nos narra que, yendo el protagonista desde Alcalá a Segovia, se encuentra con un hombre, con el que mantiene una larga conversación, en la que hay referencias burlescas a la doctrina (sobre todo, en la parte matemática) de Pacheco de Narváez. Esta vez se trata de un seguidor de las teorías pachequistas, dado que se presenta como «diestro verdadero» y porta el libro de las Grandezas de la espada, que no es otro que el publicado por el baezano en 1600 . 
Con estas pláticas y desconciertos, llegamos a Torrejón, donde se quedo [un arbitrista], que venía a ver una parienta suya.

Yo pasé adelante, pereciéndome de risa de los arbitrios en que ocupaba el tiempo, cuando, Dios y enhorabuena, desde lejos, vi una mula suelta, y un hombre junto a ella a pie, que, mirando a un libro, hacía unas rayas que medía con un compás. Daba vueltas y saltos a un lado y a otro, y de rato en rato, poniendo un dedo encima de otro, hacía con ellos mil cosas saltando. Yo confieso que entendí por gran rato -que me paré desde lejos a verlo- que era encantador, y casi no me determinaba a pasar. Al fin, me determiné, y, llegando cerca, sintióme, cerró el libro, y, al poner el pie en el estribo, resbalósele y cayó. Levantéle, y díjome: — «No tomé bien el medio de proporción para hacer la circumferencia al subir". Yo no le entendí lo que me dijo y luego temí lo que era, porque más desatinado hombre no ha nacido de las mujeres.

Preguntóme si iba a Madrid por línea recta, o si iba por camino circumflejo. Yo, aunque no lo entendí, le dije que circumflejo. Preguntóme cúya era la espada que llevaba al lado. Respondíle que mía, y, mirándola, dijo:

«Esos gavilanes habían de ser más largos, para reparar los tajos que se forman sobre el centro de las estocadas». Y empezó a meter una parola tan grande, que me forzó a preguntarle qué materia profesaba. Díjome que él era diestro verdadero, y que lo haría bueno en cualquiera parte. Yo, movido a risa, le dije: - Pues, en verdad, que por lo que yo vi hacer a v. m. en el campo denantes, que más le tenía por encantador, viendo los círculos". - "Eso» - me dijo- «era que se me ofrecí́ una treta por el cuarto círculo con el compás mayor, cautivando la espada para matar sin confesión al contrario, porque no diga quién lo hizo, y estaba poniéndolo en términos de matemática». " ¿Es posible» -le dije yo- «que hay matemática en eso?». «No solamente matemática» -dijo-, «mas teología, filosofia, música y medicina». - «sa postrera no lo dudo, pues se trata de matar en esa arte». —No os burléis» - me dijo-, «que ahora aprendo yo la limpiadera contra la espada, haciendo los tajos mayores, que comprehenden en sí las aspirales de la espada». — No entiendo cosa de cuantas me decís, chica ni grande». - P Pues este libro las dice» -me respondió, «que se llama Grandezas de la espada, y es muy bueno y dice milagros; $y$, para que lo creáis, en Rejas que dormiremos esta noche, con dos asadores me veréis hacer maravillas. $Y$ no dudéis que cualquiera que leyere en este libro, matará a todos los que quisiere». - "U ese libro enseña a ser pestes a los hombres, u le compuso algún doctor». - ¿Cómo doctor? Bien lo entiende» -me dijo-: «es un gran sabio, y aun, estoy por decir, más". 
En estas pláticas, llegamos a Rejas. Apeámonos en una posada $y$, al apearnos, me advirtió con grandes voces que hiciese un ángulo obtuso con las piernas, y que, reduciéndolas a líneas paralelas, me pusiese perpendicular en el suelo. El huésped, que me vio reír y le vio, preguntóme que si era indio aquel caballero, que hablaba de aquella suerte. Pensé con esto perder el juicio. Llegóse luego al huésped, y díjole: - «Señor, déme dos asadores para dos o tres ángulos, que al momento se los volveré». —iJesús!» —dijo el huésped—, «déme v. m. acá los ángulos, que mi mujer los asará; aunque aves son que no las he oído nombrar». - “QQué! ¡No son aves!»; dijo volviéndose a mí: - Mire v. m. lo que es no saber. Déme los asadores, que no los quiero sino para esgrimir; que quizá le valdrá más lo que me viere hacer hoy, que todo lo que ha ganado en su vida». En fin, los asadores estaban ocupados, y hubimos de tomar dos cucharones.

No se ha visto cosa tan digna de risa en el mundo. Daba un salto y decía: - «Con este compás alcanzo más, y gano los grados del perfil. Ahora me aprovecho del movimiento remiso para matar el natural. Esta había de ser cuchillada, y éste tajo». No llegaba a mí desde una legua, y andaba alrededor con el cucharón; y como yo me estaba quedo, parecían tretas contra olla que se sale. Díjome al fin: - «Esto es lo bueno, y no las borracherías que enseñan estos bellacos maestros de esgrima, que no saben sino beber".

No lo había acabado de decir, cuando de un aposento salió un mulatazo mostrando las presas, con un sombrero enjerto en guardasol, y un coleto de ante debajo de una ropilla suelta y llena de cintas, zambo de piemas a lo águila imperial, la cara con un per signum crucis de inimicis suis, la barba de ganchos, con unos bigotes de guardamano, y una daga con más rejas que un locutorio de monjas. Y, mirando al suelo, dijo: - Yo soy examinado y traigo la carta, y, por el sol que calienta los panes, que haga pedazos a quien tratare mal a tanto buen hijo como profesa la destreza». Yo que vi la ocasión, metime en medio, y dije que no hablaba con él, y que así no tenía por qué picarse. —uMeta mano a la blanca si la trae, y apuremos cuál es verdadera destreza, y déjese de cucharones».

El pobre de mi compañero abrió el libro, y dijo en altas voces: - Este libro lo dice, y está impreso con licencia del Rey, y yo sustentaré que es verdad lo que dice, con el cucharón y sin el cucharón, aquí y en otra parte, y, si no, midámoslo». Y sacó el compás, y empezó a decir: - «Este ángulo es obtuso». Y entonces, el maestro sacó la daga, y dijo: - "Yo no sé quién es Ángulo ni Obtuso, ni en mi vida oí decir tales hombres; pero, con ésta en la mano, le haré yo pedazos».

Acometió al pobre diablo, el cual empezó a huir, dando saltos por la casa, diciendo: «No me puede dar, que le he ganado los grados de 
perfil». Metímoslos en paz el huésped y yo y otra gente que había, aunque de risa no me podía mover.

Metieron al buen hombre en su aposento, y a mí con él; cenamos, y acostámonos todos los de la casa. Y, a las dos de la mañana, levántase en camisa, y empieza a andar a escuras por el aposento, dando saltos y diciendo en lengua matemática mil disparates. Despertóme a mí, $y$, no contento con esto, bajó al huésped para que le diese luz, diciendo que había hallado objeto fijo a la estocada sagita por la cuerda. El huésped se daba a los diablos de que lo despertase, y tanto le molestó, que le llamó loco. Y con esto, se subió y me dijo que, si me quería levantar, vería la treta tan famosa que había hallado contra el turco y sus alfanjes. Y decía que luego se la quería ir a enseñar al Rey, por ser en favor de los católicos.

En esto, amanecio; vestímonos todos, pagamos la posada, hicímoslos amigos a él y al maestro, el cual se apartó diciendo que el libro que alegaba mi compañero era bueno, pero que hacía más locos que diestros, porque los más no lo entendían.

Capítulo II «De lo que me sucedió hasta llegar a Madrid, con un poeta»

Yo tomé mi camino para Madrid, y él se despidió de mí por ir diferente jornada. $Y$ ya me estaba apartado, volvió con gran prisa, $y$, llamándome a voces, estando en el campo donde no nos oía nadie, me dijo al oído: - «Por vida de v. m., que no diga nada de todos los altísimos secretos que le he comunicado en materia de destreza, y guárdelo para sí, pues tiene buen entendimiento». Yo le prometí de hacerlo; tornóse a partir de mí, y empecé a reírme del secreto tan gracioso.

(El Buscón, edic. de Domingo Ynduráin, Madrid, Cátedra, 1980, pp. 150-157).

Como puede apreciarse, la crítica apunta esta vez de forma inequívoca hacia el maestro baezano, si bien a través de un seguidor de su doctrina, que cree todo lo que se dice en su Libro de las grandezas de la espada y que, además, es puesto en ridículo por el "mulatazo», también maestro de esgrima, aunque representante de la destreza conocida como «vulgar» o «primitiva». Pero, aparte de esto, se observa que el referido personaje cae en una situación grotesca, que en buena medida recuerda el incidente ocurrido entre Quevedo y Pacheco, tal y como lo relata Tarsia. No voy a insistir en las coincidencias con el texto anterior, a las que ya he aludido.

Si a ello unimos ahora el contexto de la novela en el que se inscribe el episodio en cuestión, con un protagonista del mundo picaresco para poner en en- 
tredicho tanto la teoría como la práctica por la que se guía este maestro de esgrima, el alcance satírico se vuelve aún más hiriente. Piénsese, por ejemplo, en lo grotesco de la demostración que se hace, no ya con asadores (que se podrían asemejar más a una espada), sino con cucharones; como también que tenga que ser un «mulatazo» quien lo ponga en evidencia, detalle que nos hace recordar al «negro» que descubre la verdad en el ejemplo XXXII del Conde $\mathbf{L u}$ canor de don Juan Manuel, retomado posteriormente por Cervantes en El retablo de las maravillas. Y ya que hablo de Cervantes, creo que a nadie se le escapa el paralelismo entre este episodio y otros muchos del Quijote, donde el huésped y otros clientes de una posada contemplan, atónitos y burlones, los alardes de un hombre que no parece estar en su sano juicio y que intenta llevar a la práctica lo que lee en un libro. Evidentemente, no pretendo establecer un parangón entre el famoso caballero andante y este maestro de esgrima, sino simplemente apuntar las similitudes que ofrece este pasaje quevedesco con varios episodios del inmortal relato cervantino.

En cualquier caso, el texto al que ahora nos referimos supone un ataque directo y certero: se parodia y ridiculiza la doctrina pachequista sobre la destreza de las armas. Y esto se hace en un contexto picaresco, que contrasta abiertamente con la seriedad que, lógicamente, procuraba dar a sus escritos el maestro de esgrima baezano, quien sin duda tuvo que sentirse muy molesto por este pasaje; incluso mucho más que por el percance sufrido en casa del Presidente de Castilla.

\section{3." La hora de todos}

Aunque de menor alcance significativo para el caso que nos ocupa, conviene recordar también un pasaje de esta obra en el que es clara la alusión de Quevedo al título de un capítulo del Libro de las grandezas de la espada de Pacheco («Cómo se defenderá el que trajere espada, de un turco y su alfanje. Es punto muy importante y curioso»; Madrid, Herederos de Juan Íñiguez de Lequerica, 1600, fol. 233). Dentro del marco dedicado al Gran Turco, entre las sugerencias que hace un mahometano al emperador, se encuentra ésta:

Lo tercero, que para mejor uso del rompimiento en las batallas se dejen los alfanjes corvos por las espadas de los Españoles, pues son en la ocasión para la defensa y la ofensa más hábiles, ahorrando con las estocadas grandes rodeos de los movimientos circulares, por lo cual, llegando a las manos con los Españoles, que siempre han usado mucho mejor que todas las naciones esta destreza, hemos padecido gran- 
des estragos, y son las espadas mucho más descansadas al pulso y a la cinta.

(La hora de todos y la Fortuna con seso, edic. de Jean Bourg, Pierre Dupont y Pierre Geneste, Madrid, Cátedra, 1987, pp. 297-298 [Cuadro XXXV «El Gran Turco», pp. 295-306]).

El Emperador de los Turcos manda reunir a todos sus más estrechos colaboradores. Entre ellos se presenta un morisco de los expulsados de España, quien, sirviéndose de los conocimientos adquiridos aquí, ofrece una serie de recomendaciones a su monarca en orden al engrandecimiento de su nación: $1 .^{\circ}$ ) Al igual que Grecia, Roma y España, dotar Universidades y Estudios, señalar premios a las Letras...; $2 .^{\circ}$ ) Que se admita y practique el derecho y leyes de los Romanos...; $3 .^{\circ}$ ) [el que acabamos de ver]; $4 .^{\circ}$ ) Para conservar la salud, beber vino - moderadamente-, ya que es la mejor medicina.

La ironía de la referida recomendación que hace el morisco al Gran Turco, teniendo presente el citado capítulo del libro de Pacheco, quizá se entienda mejor si volvemos al final del pasaje ya comentado del Buscón: Y con esto, se subió -el maestro de esgrima seguidor de Pacheco-y me dijo que, si me quería levantar, vería la treta tan famosa que había hallado contra el turco y sus alfanjes. Y decía que luego se la quería ir a enseñar al Rey, por ser en favor de los católicos. (Edic. cit., pp. 155-156).

Vemos, una vez más, la estrecha relación entre dos textos quevedescos. Tenemos de nuevo, pues, un dardo envenenado contra las teorías de quien alardeaba de su título de «maestro mayor de las armas» y de haber sido maestro de armas del propio rey.

4. Poema heroico de las necedades y locuras de Orlando el Enamorado, Canto I, estrofas $40 .^{\mathrm{a}}-44$. $^{\mathrm{a}}$

Esta composición, que Crosby fecha entre 1626-1628, ha sido considerada como una de las cumbres de la parodia áurea. Ignacio Arellano dice a este respecto: «buena parte de su eficacia reductora y degradación expresiva se apoya en la presencia del cliché coloquial brutalmente opuesto al arquetipo heroicons.

Como ya demostró hace años Emilio Alarcos en un memorable artículo, Quevedo se inspiró, más que en el célebre poema de Ariosto, en el Orlando In-

3 «Notas sobre el refrán y la formula coloquial en la poesía burlesca de Quevedo», La Perinola, I, 1997, pp. 15-38 (la cita corresponde a la p. 23). 
namorato de Boyardo, a quien sigue muy de cerca ${ }^{6}$. Concretamente, sobre el pasaje que vamos a comentar, diremos que estamos en un banquete ofrecido por Carlomagno, en su corte, al que asisten reyes, duques, marqueses y afamados caballeros. Reinaldos de Montalbán - sigo a E. Alarcos (art. cit., pp. 38-39) - se da cuenta de que los ricos invitados hacen befa de su modesto atuendo, por lo que les dirige por lo bajo fieras amenazas. Según Boyardo (I, 15-20), el rey Balugante, que observaba a Reinaldos, adivina el motivo del desasosiego del paladín y le pregunta por intermedio de un intérprete si en la Corte de Carlomagno se honraba a los caballeros por su ropa o por su valor. Reinaldos le responde que, si bien los glotones son estimados en la mesa y las cortesanas en el lecho, siempre se hace a los caballeros la honra que merecen por su valentía. Quevedo modifica la situación. Convierte al anónimo intérprete en don $\mathrm{Hez}$-el maestro de esgrima Narváez-, y le aplica los calificativos más groseros. Don Hez, que está junto a Reinaldos, ha oído las amenazas que mascullaba el paladín y, correveidile de chismes, se las transmite al rey Balugante. Y entonces éste le da el encargo de dirigir al paladín la pregunta antes mencionada.

En esta ocasión se da un paso más en la crítica antipachequista, puesto que no se trata simplemente de burlarse de los seguidores del maestro de esgrima, sino de atacarlo directamente, incluso con insultos personales, dirigidos en una línea habitual en Quevedo, quien sitúa al baezano en el gremio de los comudos y adúlteros.

Téngase presente que nos hallamos ante una composición paródica sobre los héroes del ciclo carolingio. De haberse quedado en la simple presencia de Pacheco de Narváez en tal ambiente, habría que considerarlo como una comparsa menor de los famosos héroes épicos. Pero se da la casualidad de que el protagonista es Orlando el Enamorado, ocasión que da pie a nuestro autor para entrar en otro terreno, el del amor, agregando de esta manera un nuevo ingrediente al ataque burlesco. Veamos ya el texto:

A las espaldas de Reinaldo estaba, más infame que azote de verdugo, un maestro de esgrima que enseñaba nueva destreza, a güevo y a mendrugo: don Hez, por su vileza, se llamaba, descendiente de carda y de tarugo,

- «El Poema herocio de las necedades y locuras de Orlando el Enamorado», en Homenaje a Quevedo en su Centenario (1645-1945), Valencia, Mediterráneo, 1946, pp. 25-63. 
a quien, por lo casado y por lo vario, llamó el emperador Cuco Canario.

Era embelecador de geometría, y estaba pobre, aunque le daban todos; ser maestro de Carlos pretendía; pero, por ser cornudo hasta los codos, su testa ángulos corvos esgrimía, teniendo las vacadas por apodos; éste, oyendo a Reinaldos, al instante lo dijo al rey famoso Balugante.

Díjole Balugante al maestrillo (pasándole la mano por la cara): «Dile al señor de Montalbán, Cuquillo, que mi grandeza su inquietud repara; que pretendo saber, para decillo, si en esta mesa soberana y clara se sientan por valor o por dinero, por dar su honor a todo caballero».

Reinaldos respondi6: «Perro judío, dirás al rey que, en esta ilustre mesa, el grande emperador, glorioso y pío, honrar todos los huéspedes profesa; que, después, la batalla y desafío quien es el caballero lo confiesa: que, a no tener respeto, las cazuelas y platos le rompiera yo en las muelas».

El falso esgrimidor, que le escuchaba, en galardón ${ }^{7}$ su natural vileza, de mala gana la respuesta daba; viendo que en su maldad misma tropieza, Galalón, que los chismes acechaba, no levanta del plato la cabeza, y el desdichado plato se retira, y a los diablos se da de que le mira.

(Poesía original completa, edic. de José Manuel Blecua, Barcelona, Planeta, 1990, canto I, estrofas 40."- 44.", vv. 313-352, pp. 12311232).

Aunque se sale de nuestro cometido, recordaré que más adelante encontramos una mención a otro famoso maestro de esgrima: mas Ferragut, que en sueños

${ }^{7}$ En texto Galalón. Astrana Marín enmendó galalonó. Blecua, sin embargo, sigue a E. Alarcos. 
vio a Carranza (Canto II, v. 292, edic. cit., p. 1257). Se trata de Jerónimo de Carranza, tratadista anterior a Pacheco, cuyas teorías trató de corregir éste.

Sería interesante, para comprender todo alcance significativo del cuadro pintado aquí por Quevedo, conocer algunos pormenores de la vida del baezano. Cuando antes trazaba su esbozo biográfico lamentaba no tener los suficientes datos sobre la situación familiar de Pacheco, fuera de la constatación en el acta de defunción de su condición de «viudo». Sin embargo, a pesar de mis intentos, no he podido averiguar nada sobre su esposa, cuándo y con quién se casó, y, por consiguiente, cómo fue su relación matrimonial.

Quevedo acude a un viejo tópico para referirse al marido burlado y al adúltero: el apelativo de «cuco» o «cuclillo» (aquí figuran «Cuco» y «Cuquillo»). Sebastián de Covarrubias, al recoger en su célebre Tesoro este segundo vocablo, apunta la creencia popular de que dicha ave acostumbra a poner los huevos en el nido de otra, para que ésta crie a sus hijos. $Y$ agrega: «Esto mesmo haze el adúltero, cuando la adúltera ha concebido dél, y el marido cría y alimenta el hijo que pare, creyendo ser suyo». Cuando Quevedo dice que Pacheco era llamado «Cuco Canario», lo segundo se entiende, ya que fue «sargento mayor» en Canarias. ¿Pero fue allí donde estuvo casado y tuvo lugar la infidelidad matrimonial por parte de uno de ellos o de los dos? ¿Dejó abandonada a su mujer en el archipiélago al establecerse en Madrid? $¿ \mathrm{O}$ fue esta ciudad el escenario del adulterio? Incluso me atrevo a formular otra pregunta: $¿$ se trata de un simple insulto sin fundamento real? No tengo datos para poder contestar. En cualquier caso, cabría también interpretar lo de «Cuco Canario» como un juego verbal con el nombre de dos aves: la primera en referencia a su condición de marido adúltero y la segunda (un gentilicio) al lugar de procedencia; resaltando, en este caso, el contraste entre ambas: la de dulce canto (canario) y la de canto desagradable y engañoso (cuco).

Hay una letrilla satírica de Quevedo que incide en esta misma línea. Éste es su cantarcillo inicial: «Sabed, vecinas, / que mujeres y gallinas / todas ponemos,/ unas cuernos y otras huevos». En la 2. a estrofa dice : «Y cuando llegan al fallo / en Cuclillos los volvemos», lo que coincide con lo visto anteriormente en nuestro poema (Poesía varia, edic. de James O. Crosby, Madrid, Cátedra, 1994, pp. 267-268).

El insulto llega a términos hiperbólicos: «... por ser cornudo hasta los codos, / su testa ángulos corvos esgrimía, / teniendo las vacadas por apodos». El Diccionario de Autoridades recoge esta entrada: Vacada: manada de ganado vacuno, que apoya precisamente en el texto de Quevedo que ahora estamos analizando. Especial valor tiene el verso («su testa ángulos corvos esgrimía»), muy denso desde el punto de vista semántico: los «ángulos» aluden a la terminología típica de los tratados pachequistas, en tanto que con el adjetivo «cor- 
vos" se refiere a los cuernos (en sentido figurado, claro está); pero hay una paradoja: los cuernos son corvos, pero no pueden formar ángulo. También se puede apreciar un doble sentido en el verbo "esgrimir»: mostrar (los atributos identificadores del hombre burlado) y hacer ejercicios de esgrima (con dichos atributos; con lo que hay, también, una animalización: hace los ataques como un animal con cornamenta).

En cuanto al verso «Ser maestro de Carlos pretendía», podría pensarse en una referencia al príncipe Baltasar Carlos (primer hijo varón de Felipe IV, inmortalizado por Velázquez), nacido en 1629 y muerto en 1646; aunque ello nos obligaría a retrasar la fecha del poema. Pero no es así, dado que se trata del gran Carlomagno, personaje - como ya he dicho- que preside el banquete, con lo cual aumenta el alcance caricaturesco ofrecido por Quevedo, quien seguramente se está burlando de la hoja de servicios del baezano, siempre ufano de haber sido maestro de armas del rey Felipe IV. Téngase presente que el nombre de este monarca se asociaba con los de Carlos y Alejandro, puesto que eran los dos que habían llevado el sobrenombre de «Magno» (Carlomagno -es el caso presente- y Alejandro Magno).

Pero hay más detalles dignos de comentario. Lo de «que enseñaba nueva destreza» es una clara alusión malévola a que Pacheco en sus tratados gustaba hablar de «nueva destreza», ya que se tenía por innovador teórico, frente a la doctrina del hasta entonces indiscutible Jerónimo de Carranza. Repárese, por ejemplo, en los título de dos obras del baezano: Modo fácil y nuevo para examinarse los maestros en la destreza de las armas y Nueva ciencia y filosofía de la destreza de las armas.

El ataque personal llega hasta el juego con el nombre de su rival: «don Hez (última silaba de Narváez), por su vileza, se llamaba». Remarco lo de «vileza», que coincide con la explicación que ofrece Covarrubias del vocablo: «De qualquiera cosa llamamos hez: el desecho tomado de las cosas líquidas, que hazen assiento en lo baxo, las hezes; la hez del pueblo, la gente vil (el subrayado es mío) y ruin, sin honra y sin término».

Ello concuerda también con «carda», ya que en germanía se decía «hombre de la carda» por «jaque» o «valentón»; de ahí el verso siguiente: «descendiente de carda y de tarugo». Aunque puede tomarse el nombre de «carda» en su sentido de «cabeza espinosa, a manera de erizo, de la cardencha» (Covarrubias) y, por similitud, tabla con clavos para cardar la lana; con una clara connotación negativa, al igual que en «tarugo», que todavía perdura hoy en nuestra lengua.

Con esta palabra juega Quevedo en la jácara «Carta de Escarramán a la Méndez»: «Hallé dentro a Cardeñoso, / hombre de buena verdad, / manco de tocar las cuerdas / donde no quiso cantar» (Poesía varia, ed. de Crosby, p. 
299). El nombre «Cardeñoso» alude a la expresión «hombre de la carda» (igual a «jaque» o "valentón») y el verso «donde no quiso cantar» está relacionado con el cuclillo.

Nuevamente vuelve Quevedo a poner en solfa los fundamentos matemáticos de sus teorías sobre esgrima, como en textos anteriores; de ahí que afirme que «Era embelecador de geometría».

Señalaba más arriba las dificultades económicas que acompañaron en vida al baezano. Pues bien, Quevedo repara en ellas y no duda en proclamar: «y estaba pobre, aunque le daban todos».

Con esto quizá se entienda mejor una afirmación anterior: «un maestro de esgrima que enseñaba / nueva destreza a güevo y a mendrugo»; es decir, hacía su trabajo por un precio muy módico y, además, en especie (por un huevo y un mendrugo de pan), lo que demuestra que eran tenidas en muy poca estima sus teorías sobre la «nueva destreza»; todo lo cual concuerda con la situación de precariedad económica que acabamos de ver.

5. Las valentonas y destreza (baile)

Estamos -como es sabido- ante una breve pieza dramática, generalmente escenificada con acompañamiento musical, de las que solían completar el programa en las funciones teatrales de la época. En este caso la acción se presenta «en el Corral de las armas» (v. 23), que vendría a ser una improvisada escuela de esgrima. Aparece en primer lugar el narrador, quien nos va haciendo la presentación de los personajes que sucesivamente entran en escena: las «valentonas» Corruja y Carrasca (nombres de dos bailes de la época), que entablan un breve diálogo, a las que sigue Maripizca la Tamaña (oxímoron onomástico); luego aparece Santurde (nombre de otro baile) el de Ocaña, hombre de aspecto horripilante, $y$, finalmente, un maestro de esgrima. Las tres valentonas hacen alardes de sus habilidades, lanzando amenazas mientras bailan. De la misma forma proceden los dos personajes masculinos, siendo el maestro el encargado de dar remate a esta particular lección de esgrima. Ahora bien, diversas apostillas del narrador van revelando que tanto ellas como ellos son simples rufianes y ladrones.

[Las valentonas, $y$ Destreza] [Baile]

Helas, helas por do vienen

La Corruja y la Carrasca,

A más no poder mujeres, 
Hembros de la vida airada.

Mortales de miradura

Y ocasionadas de cara,

$E l$ andar a lo escocido,

El mirar a lo de l' Hampa.

Llevan puñazos de ayuda

Como perrazos de Irlanda,

Avantales voladores,

Chapinitos de en volandas.

Sombreros aprisionados

Con porquerón en la falda,

Guedejitas de la tienda,

Colorcita de la plaza.

Mirándose a lo penoso,

Cercáronse a lo borrasca;

Hubo hocico retorcido,

Hubo agobiado de espaldas.

Ganaron la palmatoria

En el Corral de las armas,

Y encaramando los hombros,

Avalentaron las sayas.

Corruja: $\quad$ «De las de la hoja

Soy flor y fruto,

Pues a los talegos

Tiro de puño.»

Carrasca: «Tretas de montante

Son cuantas juego;

A diez manos tomo

Y a dos peleo."

Luego, acodada de rostro

$Y$ ahigadada de cara,

Un tarazón de mujer,

Una brizna de muchacha.

Entró en la escuela del juego

Maripizca la Tamaña,

Por quien Ahorcaborricos

Murió de mal de garganta

Presumida de ahorcados

Y preciada de gurapas,

Por tener dos en racimo

$Y$ tres patos en el agua, 
Con valentía crecida

Y con postura bizarra

Desembrazando a los dos,

En esta manera garla:

[Maripizca] «Llamo uñas arriba

A cuantos llamo,

$Y$ al recibo los hiero

Uñas abajo.

«Para el que me embiste

Pobre y en cueros,

Siempre es mi postura

Puerta de hierro.»

Rebosando valentía

Entró Santurde el de Ocaña,

Zaino viene de bigotes

$\mathrm{Y}$ atraidorado de barba.

Un locutorio de monjas

Es guamición de la daga,

Que en puribus trae al lado

Con más hierro que Vizcaya.

Capotico de Antemulas,

Sombrerico de la carda,

Coleto de por el vivo,

más probado que la pava.

Entró de capa caída,

Como los valientes andan

Azumbrada la cabeza

Y bebida la palabra:

[Santurde] «Tajo no le tiro,

Menos le bebo;

Estocadas de vino

Son cuantas pego.»

Una rueda se hicieron;

¿Quién duda que de navajas?

Los codos tiraron cozes,

Azogáronse las plantas;

Trastornáronse los cleerpos,

Desgoznáronse las arcas;

Los pies se volvieron locos,

Endiabláronse las plantas. 
No suenan las castañetas,

Que de puro grandes, ladran,

Mientras al son se concomen,

Aunque ellos piensan que bailan.

Maripizca tomó el puesto,

Santurde tomó la espada,

Con el montante el Maestro

Dice que guarden las caras.

[Maestro] «De verdadera destreza

Soy Carranza,

Pues con tocas y alfileres

Quito espadas.

"Que tengo muy buenos tajos

Es lo cierto,

$\mathrm{Y}$ algunos malos reveses

También tengo.

«El que quisiere triunfar,

Salga de oros,

Que el salir siempre de espadas

Es de locos.»

Maestro «Siente ahora la Corruja.»

Corruja «Aquesta venida vaya.»

Maestro «Jueguen destreza vuarcedes.»

Santurde «Somos amigos, y basta.»

Maestro «No es juego limpio brazal.»

Corruja «Si no es limpio, que no valga.»

Maestro «Siente vuarced.»

Santurde «Que ya siento,

Y siento pese a su alma.»

Tornáronse a dividir

En diferentes escuadras,

$\mathrm{Y}$ denodadas de pies,

Todas juntas se barajan.

Cuchilladas no son buenas,

Puntas si de la joyeras.

[Maestro] «Entráronme con escudos,

Cansáronme con rodelas;

Cobardía es sacar pies,

Cordura sacar moneda. 
«Aguardar es de valientes

Y guardar es de discretas,

La herida de conclusión

Es la de la faltriquera.»

Cuchilladas no son buenas,

Puntas sí de las joyeros.

[Maestro] «Ángulo agudo es tomar,

No tomar, ángulo bestia;

Quien viene dando a mi casa,

Se viene por línea recta.

«La universal es el dar;

Cuarto círculo, cadena;

Atajo, todo dinero

Rodeo, toda promesa.»

Cuchilladas no son buenas,

Puntas si de las joyeras.

[Maestro] «El que quisiere aprender

La destreza verdadera,

En este poco de cuerpo

Vive quien mejor la enseña."

(Poesía varia, edic. de James O. Crosby, Madrid, Cátedra, 1994, pp. 332-341).

L. Astrana Marín entendió en su día que este baile se había escrito para mortificar a Pacheco (nota $6 .^{a}$ ), si bien considera que el verdadero título no es «Las valentonas y destreza» (dado por González de Salas en el Parnaso espa$\tilde{n} o l$, sino «Baile de las armas», y así lo incluye en su edición de Obras completas. Verso (1932, pp. 520-522; 1943, pp. 507-509). Y J. O. Crosby, por su parte, afirma lo siguiente: «no es difícil entender este baile como caricatura del maestro de armas Luis Pacheco de Narváez», de quien se había burlado Quevedo en textos anteriores (edic. cit., p. 342).

En efecto, toda la pieza consiste en una exhibición - paródica, por supuesto- sobre la teoría de la destreza de las armas. Expresiones como «por línea recta», «destreza verdadera» o «cuarto círculo» (que ya hemos visto en otros textos quevedescos) son claras referencias a la fraseología típica de los tratados de Pacheco de Narváez. Por otro lado, el hecho de que intervengan personajes grotescos habituales en los «bailes», sobre todo las mujeres «valentonas» (posiblemente en alusión al baile de la época conocido como «Las va- 
lientas»), constituye un punto más en la degradación, puesto que la condición de «valentón» se consideraba exclusiva del hombre. Si a ello unimos la presencia del espadachín Santurde, cuyo físico concentra todo tipo de elementos negativos, las enseñanzas finales del maestro de esgrima (entiéndase Pacheco de Narváez) se convierten en puro esperpento, dado que, en definitiva, al igual que el resto de los personajes, resulta ser un vulgar rufián.

Ya antes habíamos visto ridiculizado al baezano en un ambiente picaresco (ElBuscón). pero podíamos entender que aquel maestro de esgrima seguidor de Pacheco era un pobre loco que intentaba llevar a la práctica las enseñanzas del libro de éste y que incluso se sentía extraño en el mundo del hampa. Ahora se baja un peldaño más. La situación sigue siendo igualmente degradante, pero a ello se agrega que el maestro de armas es otro ladrón y fanfarrón más.

\section{6." Entremés de la destreza}

Estamos ante un caso muy similar al anterior, incluida la presencia de personajes femeninos. Nuevamente se nos presenta un desfile de «valentonas» que muestran ante el público sus habilidades en el manejo de las armas; con independencia de otros interesantes datos sobre compañías teatrales de la época que no vienen ahora al caso.

Veamos algunos fragmentos relativos al tema que nos ocupa.

\section{Chillona.-...}

De lo vulgar, soy grande embestidora de cualquier faltiquera,

y pretendo saber la verdadera.

\section{Pitorra.- ...}

No se descuida Prado

pues en su compañía

trai a la madre Monda,

vieja que de don Luis y de Carranza

tiene todos los textos en la panza.

Madre.-

Destreza verdadera

no partir con amiga ni tercera.

\section{Madre.-}

Medio de proporción más verdadero es, Chillona, el dinero. 
La destreza de todos siempre ha sido

-así vulgares como verdaderos-

dar y no recibir. ...

(Obra poética, edic. de José Manuel Blecua, T. IV, Madrid, Castalia, 1981, pp. 103-109, vv. 11-13, 41-45, 58-59 y 76-80).

De nuevo se mezclan el mundo del hampa y el de la destreza de las armas. Sin embargo, el ataque contra Pacheco no es ahora directo, puesto que la cita que hace Pitorra de él, junto al nombre de Carranza (célebre tratadista sevillano anterior al baezano), podía entenderse, en principio, como positivo. Ahora bien, el hecho de que el tema de la destreza - tan serio para él - sea llevado a un entremés y, en consecuencia, puesto en escena por personajes de baja condición social, supone un punto de degradación más que notable.

Véase cómo aquí se pone en solfa tanto a los partidarios de la destreza «vulgar» como de la llamada «verdadera»; pero muy en particular a los de esta última (con varias alusiones), cuyo máximo exponente era el propio Pacheco de Narváez. Es lo más grave que se podía decir de los libros del baezano: sus teorías sólo servían para ser ridiculizadas por ladrones y rufianes del «sexo llamado débil».

Como puede comprobarse por estos dos últimos textos comentados, estamos no ante episodios o pasajes concretos de obras (caso de los cuatro ejemplos primeros), sino de dos piezas que, si bien son de extensión menor, en su totalidad están dedicadas a la burla de la destreza de las armas. El ataque contra Pacheco de Narváez no es tan grotesco y punzante como el del Buscón, ni llega a los extremos insultantes del Poema de Orlando; ahora bien, el alcance satírico no resulta desdeñable. El simple hecho de la escenificación por parte de los personajes típicos de estas piezas menores, orientadas al regocijo de los asistentes al espectáculo teatral de la época, suponía, ya de por sí, un motivo de mofa; máxime si, además, se trataba de un asunto serio, al menos para los teóricos de esgrima. La sátira antipachequista no sólo llegaba a los selectos lectores de obras cultas (los cuatro ejemplos anteriores), sino también al pueblo llano que acudía a los corrales.

\section{Conclusión}

Considero que el muestrario de textos ofrecidos es bastante variado y suficientemente ilustrativo de la técnica quevedesca en el manejo de la sátira, en particular cuando se dirigía —es nuestro caso- contra una persona concreta. Además, me parece oportuno insistir en la interrelación existente entre los textos de Quevedo analizados. 
Su proceder es diametralmente diferente al seguido por su rival. Los escritos de Pacheco de Narváez se orientan en dos direcciones fundamentales: a) Denunciar las obras del madrileño ante el tribunal de la Inquisición (ésta era la pretensión del Memorial); b) Desmontar la base argumental de la Política de Dios, lo que llevaba implícita una denuncia ante el Santo Oficio, y, de paso, poner en evidencia la actitud de Quevedo ante el rey y su poderoso valido (en Peregrinos discursos).

El baezano nunca entró en el mismo campo de batalla de su contrincante, salvo si admitimos la patemidad de El tribunal de la justa venganza, que, por su atrevimiento, resulta más quevedesco. Eso sí, se permitió devolver al adversario la misma moneda: nunca menciona su nombre. En Quevedo sólo hemos visto el juego verbal que le proporciona uno de los apellidos: cuando le llama «don Hez».

El escritor madrileño prefiere el ataque directo en una lucha cuerpo a cuerpo, valiéndose de las armas del lenguaje. En realidad, era una forma más de criticar las teorías de Pacheco. Quevedo no necesitaba fundamentos teóricos y rodeos argumentativos; echaba mano de la espada de la lengua para asestar el golpe certero. Tenía, además, la experiencia del incidente en casa del Presidente de Castilla, donde había resultado vencedor sin recurrir a los tratados de esgrima. Era el triunfo de la práctica sobre la teoría.

Quevedo se burla también de los seguidores de Pacheco, que es lo peor que le puede ocurrir al maestro de cualquier disciplina. Téngase en cuenta que el baezano había sido maestro de armas de Felipe IV y más tarde, al conseguir el título oficial, tenía competencias para examinar a los futuros maestros. Hemos comprobado cómo el escritor madrileño nos presenta a personajes que se autoproclaman como «maestros examinados» y llevan consigo las credenciales correspondientes.

Significativo resulta también el hecho de que la sátira antipachequista llegue a diferentes géneros literarios, tanto en obras en prosa (ficción filosófica, novela picaresca) como en verso (poema paródico, baile y entremés), prueba inequívoca de que el madrileño se desenvolvía con soltura en todos los campos de batalla dialécticos.

Con independencia de los ataques particulares y directos que hemos visto en uno de los casos (Poema de Orlando), donde Quevedo llega al máximo en la pintura negra de su rival, considero que debe resaltarse también su especial interés por rebajar a Pacheco hasta los límites más sórdidos, mezclándolo con personajes de baja estofa (Buscón, baile y entremés). Si ofensivo es lo primero, no menos desagradable tuvo que resultar al baezano el desprecio que suponía lo segundo, teniendo en cuenta - no se olvide- que Pacheco se codeaba con lo más granado del mundo cultural madrileño de su época. 
Es evidente que los dos escritores lucharon con las armas que cada uno sabía esgrimir: Pacheco, con la denuncia y la crítica argumental; Quevedo, con el arte de la palabra, que dominaba mucho mejor. Desde el punto de vista ético, tendríamos que afirmar que parece más presentable la actitud del baezano. Pero no estamos aquí para juzgar comportamientos morales (De internis, neque Ecclesia, reza el adagio clásico), sino como estudiosos de la literatura, es decir, del arte de la palabra. Y, bajo esta perspectiva, nos vemos obligados a admitir que Quevedo poseía mayor destreza verbal. Está claro, por consiguiente, que en tan enconado enfrentamiento fue él quien, en definitiva, resultó vencedor. 